\title{
Indicators of Computer-Mediated Communication Affecting Remote Employee Engagement
}

\author{
Franklin M. Lartey ${ }^{1}$, Phillip M. Randall2* \\ ${ }^{1}$ Cox Communications, Inc., Atlanta, GA, USA \\ ${ }^{2}$ School of Business and Technology, Capella University, Minneapolis, MN, USA \\ Email: franklin@lartey.net, *Phillip.Randall@capella.edu
}

How to cite this paper: Lartey, F. M., \& Randall, P. M. (2021). Indicators of Computer-Mediated Communication Affecting Remote Employee Engagement. Journal of Human Resource and Sustainability Studies, 9, 82-92.

https://doi.org/10.4236/jhrss.2021.91006

Received: December 8, 2020

Accepted: March 6, 2021

Published: March 9, 2021

Copyright () 2021 by author(s) and Scientific Research Publishing Inc. This work is licensed under the Creative Commons Attribution International License (CC BY 4.0).

http://creativecommons.org/licenses/by/4.0/

(c) (i) Open Access

\begin{abstract}
In this study, the indicators of computer-mediated communication that affect engagement among remote knowledge workers were analyzed. After conducting an online survey of 133 remote knowledge workers in the U.S., a multiple regression statistical model was used to answer the research question seeking the extent to which empathy, expressiveness, and motivation contributed to remote employee engagement. Our findings suggested the existence of a statistically significant relationship between the independent variables Empathy, Expressiveness, and Motivation, and the dependent variable Engagement. This study contributed to knowledge by filling the gap in current literature as no previous attempt had been made on analyzing the relationship between engagement and the items identified here. Our findings have implications for researchers and practitioners in that they may assist in guiding future research and work design for remote knowledge workers in the digital and pandemic era. This study can help managers identify remote workers who need the most help. This comes from the observation that remote employees work away from their managers and colleagues and the absence of casual conversations that tend to provide directions or remind them of things to do could hinder their performance in the absence of self-determination.
\end{abstract}

\section{Keywords}

Engagement, Employee Engagement, Remote Worker, Remote Employee, Self-Determination, Computer-Mediated Communication, Empathy, Expressiveness, Motivation, Knowledge Worker 


\section{Introduction}

As a result of technological advances and the advent of the coronavirus pandemic 2019, there is a rapid growth of people developing and using technology for work. As it happens, the technology and the coronavirus pandemic of 2019 are coincidentally shaping work and people (Wang et al., 2020). Computer-mediated communications and their associated activities such as sending an email, making a video call, searching the internet, using a tablet or mobile phone, have come to greatly impact people in the workplace, notably the knowledge worker. The impact has much to say and do with the engagement of the remote knowledge worker in ways yet to be fully understood. What we do know is that the use of computer-mediated communications is gradually changing the social and relational aspects of today's work as well as the engagement of the knowledge workers (Tate, Lartey, \& Randall, 2019). What we do not know is just how impactful the changes are in terms of their effect on individual and organizational success, and what can be done to mitigate and/or enhance worker and organizational outcomes. To that effect, we identify three indicators of remote knowledge workers' competency in computer-mediated communication from a validated instrument and study their relationship with the workers' levels of engagement. As such, this study serves to reduce the gap in research by analyzing the relationship between the independent variables: empathy, expressiveness, and motivation, and the engagement of remote knowledge workers. In other words, the purpose of this study is to identify if there is a significant relationship between computer-mediated communication competencies and remote employee engagement. To achieve the stated goal, a review of the literature was conducted, explaining the concepts related to computer-mediated communications, employee engagement, and self-determination theory. This is followed by the research question, hypotheses, and conceptual framework. A methodology including the research approach and instruments used is presented, followed by data analysis, results, and the conclusion.

\section{Literature Review}

\section{Computer-Mediated Communication}

Technology has revolutionized the way business is conducted. That is, rather than rely solely on face-to-face communication, employers and their employees alike have a wide variety of technology-mediated resources at their disposal (Cascio \& Montealegre, 2016). Today's computer-mediated communication (CMC) embodies the creation and exchange of information, while previous outdated telecommunication systems require encoding, transmitting, and decoding of information (Spitzberg, 2006). This transition of technology enables communication to be more readily available and user friendly.

Spitzberg (2006) defines computer-mediated communications (CMC) as any human symbolic text-based interaction conducted or facilitated through digitally based technologies such as the Internet, cellular phone text, instant messaging 
(IM), email, and the like. CMC competence refers to whether a person can appropriately and effectively communicate with others through digitally-based technologies as the intermediary communication media (Windahl \& McQuail, 1993). It is affected by a person's communication motivation, communication knowledge, communication skills, and attentiveness (Spitzberg, 1997, 2006).

Spitzberg (2006) developed a computer-mediated communication competence model specifically to analyze the communication environment, the media type or method of exchange, and the interaction among users. He maintained that the competent user is more likely to play a significant role in the diffusion of information via the intermediary communication media. The CMC model thus measures and is a function of the CMC user's motivation, expressiveness, knowledge, and attentiveness (Spitzberg, 2006).

\section{Empathy (sub-statement of attentiveness)}

Empathy is the action of understanding, being aware of, being sensitive to, and vicariously experiencing the feelings, thoughts, and experience of another of either the past or present without having the feelings, thoughts, and experience fully communicated in an objectively explicit manner (Merriam-Webster, 2020). Associated with the definition of attentiveness, empathy means, showing care for what others need or desire even if they do not express such needs or desires. It is related to care or courteousness. Attentiveness and empathy can be displayed in CMC through a variety of tactics, including the degree to which topics initiated by others are taken up in one's own CMC message content, use and appropriateness of questions, social support and comforting sophistication of message content, and politeness and appropriateness of message content (Pratt, Wiseman, Cody, \& Wendt, 1999).

\section{Expressiveness}

Expressiveness is the demonstration, expression, or communication of feelings and thoughts. It is defined by Merriam-Webster (2020) as the quality of effectively conveying a thought or feeling. Expressiveness suggests the ability to show or communicate meaning or feelings effectively. Expressiveness skills can be displayed in CMC interactions through the use of emoticons and similar paralinguistic features of message content, the use of humor, and even the depth and breadth of self-disclosure (Castellá et al., 2000).

\section{Motivation}

Motivation is the reason or reasons one has for acting or behaving in a particular way (Merriam-Webster, 2020). According to Maslow (1954), people are motivated by unsatisfied needs. In this application, motivation is associated with a range of constructs such as willingness to adopt new communication technologies, satisfaction, gratifications, and positive attitudes toward such technologies (Wright, 2000).

Computer-mediated communication is used by employees in the execution of their daily tasks and in communicating with their managers and colleagues. To achieve company goals, managers need to ensure the engagement of their em- 
ployees through motivation, clear expression of feelings and thoughts, and the demonstration of empathy which contributes to the achievement of organizational success.

\section{Employee Engagement}

In defining employee engagement, it is suitable to look further than the traditional notions of job satisfaction, organizational commitment, job involvement, etc. According to Andrew and Sofian (2011), employee engagement involves the active use of emotional, cognitive, and behavioral efforts at work while seeking to achieve the organization's expressed objectives and strategies. Further, engaged employees are highly motivated and more likely to focus their energy towards successfully achieving organizational goals and outcomes (Macey \& Schneider, 2008). Schaufeli and Bakker (2004) report that engaged employees experience greater attachment to their work as well as the organization. Macey et al. (2011) state that "Engagement is an individual's sense of purpose and focused energy, evident to others in the display of personal initiative, adaptability, effort, and persistence toward organizational goals" (pg. 6). Lartey (2021) viewed engagement from both the employee and the employer's perspectives. He defined engagement as:

a two-way relationship between an organization and a worker, in which the organization provides the worker with the environment and conditions to be successful through good leadership and management, and the worker provides the organization with a positive and self-motivated performance leading to the achievement of the organizational mission, vision, purpose, and goals (Lartey, 2021).

Employee engagement can be measured using existing instruments such as the Utrecht Work Engagement Scale (UWES-9) created by Schaufeli, Bakker, and Salanova (2006). This instrument was used in the current study. Employee engagement can also be explained from the lens of various theories, one of them being the self-determination theory.

\section{Self Determination Theory}

Self-determination theory is a motivation theory developed by Ryan and Deci (2000) that investigates natural and intrinsic tendencies that result in effective and healthy behaviors. It is one of the commonly used approaches in recent years in psychological needs satisfaction research. This theory also specializes in employee satisfaction and motivation and is framed around three basic needs: autonomy, competence, and employee relatedness and affiliation (Ryan \& Deci, 2000).

According to the theory of self-determination, there are various factors that affect the motivation, social functioning, and personal growth of individuals. Within this framework, while the theory examines the nature of the individuals' positive development trends, it also investigates factors that contribute to this development and that prevent this development trend. The theory states that individuals basically have the potential for self-development and self-assertion. It 
argues that a person tries to engage in activities that are of interest as a development-oriented entity, and in order to create meaningful cohesion and to develop attachment and relationship within social groups (Ryan \& Deci, 2000). This study is anchored on the self-determination theory as it seeks to explain employee engagement from the standpoint of empathy, expressiveness, and motivation which are all intrinsic to the employee.

\section{Research Question, Hypotheses, and Conceptual Framework}

In seeking the indicators of computer-mediated communication that affect engagement among remote knowledge workers, the following research question was used to guide this work:

RQ: To what extent does empathy, expressiveness, and motivation as measured by their singular indicators in CMC competencies contribute to the engagement of remote knowledge workers?

To answer this research question, a hypothesis and null hypothesis were formulated.

$\mathrm{H}_{0}$ : There is no statistically significant relationship between empathy, expressiveness, motivation, and employee engagement.

$\mathrm{H}_{\mathrm{A}}$ : There is a statistically significant relationship between empathy, expressiveness, motivation, and employee engagement.

A visual representation of the research question is presented in the conceptual framework on Figure 1. It shows on the left the three independent variables (Empathy, Expressiveness, and Motivation) used to evaluate their contribution to the dependent variable shown on the right (Engagement).

\section{Methodology}

\section{Research Approach and Instrument}

To analyze the indicators of computer-mediated communication that affect employee engagement, we used a quantitative research design with a non-experimental correlational approach to inquiry as suggested by Creswell (2009). Participants were randomly selected by a survey firm and filled their

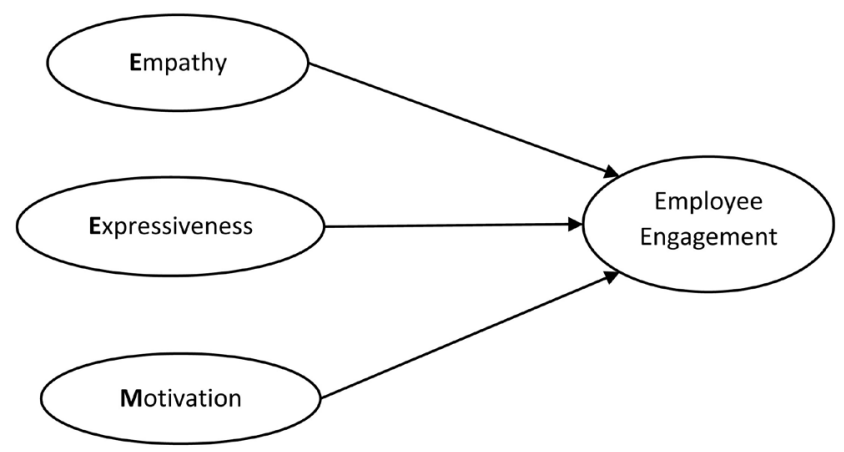

Figure 1. Theoretical framework of the study suggesting that empathy, expressiveness, and motivation might contribute to remote employee engagement. 
survey questionnaires online. The questionnaire included the Ultrecht Work Engagement Scale (UWES-9), a validated instrument for measuring employee engagement created by Schaufeli, Bakker, and Salanova (2006). The computermediated communication indicators were identified from the CMC competency scale created by Spitzberg (2006) based on the previous study and recommendation by Tate et al. (2019). The three selected indicators came from the main factors identified to drive engagement, namely attentiveness, expressiveness, and motivation. The related indicators were identified from the following assertions:

EMPATHY: I show concern for and interest in the person I am conversing with in my communications messages.

EXPRESSIVENESS: I use a lot of the expressive symbols in my communication messages e.g., :) or smiley for "smile".

MOTIVATION: I look forward to sitting down at my computer to write to others/do my daily work.

The Cronbach alpha reliability test of the resulting questionnaire showed a reliability value of .91 . Such value confirmed a high internal consistency of the survey questionnaire, allowing for the pursuit of the analysis without further data reduction.

\section{Population and Sample Size}

In conducting this study, data were collected through an online survey of a random sample of 133 remote knowledge workers across the United States of America (U.S.). As presented on Table 1, of this total number of participants, 48 were males representing 36.1 percent and 85 were females representing 64.9 percent of the sample. This sample size was deemed adequate for the study compared to similar studies. For example, Tate, Lartey, and Randall (2019) used a sample of 120 participants in their study of the relationship between computer-mediated communication competencies and employee engagement. Similarly, in a multiple regression study of drivers of employee engagement, Saks (2006) used a sample of 107 participants. In addition to prior studies, a post hoc power analysis using the statistical power analysis tool G Power 3.1.9.4 with three predictors and $\vec{f}=15$ for a medium effect size, a error probability of .05 , confirmed the achievement of a total power of .97 , well above the minimum power of .80 suggested by Fields (2013).

\section{Data Analysis}

To answer the research question seeking the extent to which empathy, expressiveness, and motivation contribute to the remote workers' engagement, a

Table 1. Participants by gender.

\begin{tabular}{ccccc}
\hline & Frequency & Percent & Valid Percent & Cumulative Percent \\
\hline Males & 48 & 36.1 & 36.1 & 36.1 \\
Females & 85 & 63.9 & 63.9 & 100.0 \\
Total & 133 & 100.0 & 100.0 & \\
\hline
\end{tabular}


multiple regression statistic model needed to be built. Prior to that, the assumptions of multiple regression were tested on the sample of the study. There was one dependent variable (DV) identified and named ENGAGEMENT. This latent variable represented the overall score of the participant's engagement measured as the sum of all subtending observations. Three observable independent variables (IV) were identified, namely EMPATHY, EXPRESSIVENESS, and MOTIVATION. All variables were measured at the scale level in SPSS. The assumptions of multiple regression were tested prior to building the model.

With 133 participants and three IVs, the number of cases to IV was well over the minimum of 107 suggested by Tabachnick and Fidell (2013). Furthermore, a descriptive statistic of the z-scores of all variables confirmed the absence of univariate outliers in the data, and there were no missing values because the final sample had been previously cleaned up after the online survey and incomplete responses expunged. The Shapiro-Wilk and Kolmogorov-Smirnov tests confirmed the normality of the dependent variable allowing for the consideration of the DV as normally distributed. The absence of multivariate outliers was confirmed using the Mahalanobis distance and the probability of the chi-square distribution with three degrees of freedom. A scatter plot of standardized residuals and standardized predicted values confirmed the normality, linearity, homoscedasticity, and independence of residuals. There was no concern for multicollinearity and singularity as confirmed by the variable inflation factor (VIF) as all values were well below 10 as shown on Table 4 . With the validation of the assumptions of multiple regression, a standard multiple regression model was created to answer the research question.

\section{Results and Discussions}

To assess the ability to predict the DV (ENGAGEMENT) using the IVs (EMPATHY, EXPRESSIVENESS, and MOTIVATION), a standard multiple regression model was created on IBM SPSS using the option Analyze > Regression > Linear. This model confirmed the existence of a significant regression equation $F$ (3, 129) $=48.17, p<.001$ as shown on Table 2 . With this confirmation, the null hypothesis was rejected, and the alternate hypothesis retained, suggesting that there was a statistically significant relationship between EMPATHY, EXPRESSIVENESS, MOTIVATION, and ENGAGEMENT.

Table 2. Analysis of variance (ANOVA) showing a significant regression equation achieved.

\begin{tabular}{ccccccc}
\hline \multicolumn{1}{c}{ Model $^{\mathrm{a}}$} & Sum of Squares & $\mathrm{df}$ & Mean Square & $\mathrm{F}$ & Sig. \\
\hline & Regression & $10,977.845$ & 3 & 3659.282 & 48.178 & $.000^{\mathrm{b}}$ \\
1 & Residual & 9797.944 & 129 & 75.953 & & \\
& Total & $20,775.789$ & 132 & & & \\
\hline
\end{tabular}

a. Dependent variable: Engagement; b. Predictors: (Constant), EMPATHY, EXPRESSIVENESS, MOTIVATION. 
The summary of the multiple regression model is presented on Table 3. The R-Square column of the table shows a value of .528, suggesting that this model explains 52.8 percent of the variability in the engagement score as measured by the UWES-9.

A view of the model coefficients as shown on Table 4 confirms that all IVs were statistically significant in their contribution to the DV $(p<.005)$. Furthermore, the standardized coefficients Beta indicate that the most significant contribution of engagement is MOTIVATION, followed by EMPATHY, then EXPESSIVENESS.

The goal of this self-determination theory-based study was to identify the relationship between the predictors EMPATHY, EXPRESSIVENESS, and MOTIVATION, and the outcome variable ENGAGEMENT. The predictors were measured using their related items in the computer mediated communication competency instrument, while the outcome variable was measured using the Utrecht Work Engagement Scale (UWES-9). An online survey was conducted on a random sample of 133 remote knowledge workers and a standard multiple regression model was built using IBM SPSS after validating the assumptions required for such model. The results confirmed that EMPATHY, EXPRESSIVENESS, and MOTIVATION had a statistically significant relationship with remote employee engagement. The model with three independent variables accounted for 52.8 percent of the variability in the remote employees' engagement levels as measured by UWES-9. The self-determination theory suggests that intrinsic forces drive motivation in employees, which contribute to their increased performance. Because remote employees work away from their managers and colleagues, the absence of casual conversations that tend to provide direction or remind them of things to do can be overcome by self-determination and intrinsic motivation driving increased performance.

Table 3. Model summary.

\begin{tabular}{ccccc}
\hline Model $^{\mathrm{a}}$ & $\mathrm{R}$ & R Square & Adjusted R Square & Std. Error of the Estimate \\
\hline 1 & $.727^{\mathrm{a}}$ & .528 & .517 & 8.715 \\
\hline
\end{tabular}

a. Predictors: (Constant), EMPATHY, EXPRESSIVENESS, MOTIVATION.

Table 4. Model coefficients.

\begin{tabular}{|c|c|c|c|c|c|c|c|c|}
\hline & \multirow{2}{*}{ Model $^{\mathrm{a}}$} & \multicolumn{2}{|c|}{$\begin{array}{l}\text { Unstandardized } \\
\text { Coefficients }\end{array}$} & \multirow{2}{*}{$\begin{array}{c}\begin{array}{c}\text { Standardized } \\
\text { Coefficients }\end{array} \\
\text { Beta }\end{array}$} & \multirow[t]{2}{*}{$\mathrm{t}$} & \multirow{2}{*}{ Sig. } & \multicolumn{2}{|c|}{$\begin{array}{l}\text { Collinearity } \\
\text { Statistics }\end{array}$} \\
\hline & & B & Std. Err & & & & Tolerance & VIF \\
\hline \multirow{4}{*}{1} & (Constant) & 1.530 & 3.445 & & .444 & .658 & & \\
\hline & EMPATHY & 3.397 & .837 & .282 & 4.059 & .000 & .759 & 1.318 \\
\hline & EXPRESSIVENESS & 2.036 & .614 & .215 & 3.317 & .001 & 867 & 1.154 \\
\hline & MOTIVATION & 5.490 & .849 & .443 & 6.465 & .000 & .778 & 1.285 \\
\hline
\end{tabular}

a. Dependent variable: Engagement. 
These findings have implications for managers, one of which is the identification of employees needing the most help for remote work settings. Indeed, asking the three main questions used in this study can help managers determine which of their employees need more assistance while working remotely, which can be very helpful with the ongoing COVID-19 pandemic and current and future requirements to work from home.

While of importance to practitioners and researchers, this study has limitations worth considering. First, it used a self-administered questionnaire suggesting the risk of bias. This risk was reduced with the implementation of algorithms that identify and exclude biased data from the final dataset, but there is no guarantee that all bias was removed. In addition, this study was conducted in the United States and its findings cannot be generalized to other countries. Future research can replicate this work in different countries to allow for a broader generalization. Additional studies can also help identify other variables that contribute to the engagement of remote knowledge workers.

\section{Conclusion}

In analyzing the items of computer-mediated communication competencies that contribute to remote employee engagement, this study reviewed the literature by explaining the concepts related to computer-mediated communication, employee engagement, and self-determination theory. It also presented the research question, hypotheses, and conceptual framework as well as the methodology which included the research approach and instruments used. Finally, the data analysis was discussed, and the results presented. These results suggested the existence of a statistically significant relationship between Employee Engagement and three items of computer-mediated communication, namely EMPATHY, EXPRESSIVENESS, and MOTIVATION. The findings of the study suggested that empathy, expressiveness, and motivation can explain 52.8 percent of variability in employee engagement, confirming their contribution to engagement.

The limitations of the study as well as implications for managers and researchers were discussed. Suggestions were made for further research, such as conducting a replication study in another country to allow for generalization of the findings. Additionally, future research could help identify items that explain the other 47.2 percent in the variability in employee engagement.

\section{Conflicts of Interest}

The authors declare no conflicts of interest regarding the publication of this paper.

\section{References}

Andrew, O. C., \& Sofian, S. (2011). Engaging People who Drive Execution and Organizational Performance. American Journal of Economics and Business Administration, 3, 569-575. https://doi.org/10.3844/ajebasp.2011.569.575

Cascio, W. F., \& Montealegre, R. (2016). How Technology Is Changing Work and Or- 
ganizations. Annual Review of Organizational Psychology and Organizational Behavior, 3, 349-375. https://doi.org/10.1146/annurev-orgpsych-041015-062352

Castellá, V. O., Abad, A. M. Z., Alonso, F. P., \& Silla, J. M. P. (2000). The Influence of Familiarity among Group Members, Group Atmosphere, and Assertiveness on Uninhibited Behavior through Three Different Communication Media. Computers in Human Behavior, 16, 141-159. https://doi.org/10.1016/S0747-5632(00)00012-1

Creswell, J. W. (2009). Research Design Qualitative, Quantitative, and Mixed Methods Approaches. Thousand Oaks, CA: SAGE Publications.

Fields, A. (2013). Discovering Statistics Using IBM SPSS Statistics. New York: Sage Publications Ltd.

Lartey, F. M. (2021). Impact of Career Planning, Employee Autonomy, and Manager Recognition on Employee Engagement. Pending Publication.

Macey, W., \& Schneider, B. (2008). The Meaning of Employee Engagement. Industrial and Organizational Psychology, 1, 3-30. https://doi.org/10.1111/j.1754-9434.2007.0002.x

Macey, W., Schneider, B., Barbera, K., \& Young, S. (2011). Employee Engagement: Tools for Analysis, Practice, and Competitive Advantage. Malden, MA: John Wiley \& Sons.

Maslow, A. (1954). Motivation and Personality. New York: Harper.

Merriam-Webster (2020) Merriam-Webster's Collegiate Dictionary. Springfield, MA: Merriam-Webster.

Pratt, L., Wiseman, R. L., Cody, M. J., \& Wendt, P. F. (1999). Interrogative Strategies and Information Exchange in Computer-Mediated Communication. Communication Quarterly, 47, 46-66. https://doi.org/10.1080/01463379909370123

Ryan, R., \& Deci, E. (2000). Self-Determination Theory and the Facilitation of Intrinsic Motivation, Social Development, and Well-Being. American Psychologist, 55, 68-78. https://doi.org/10.1037/0003-066X.55.1.68

Saks, A. M. (2006). Antecedents and Consequences of Employee Engagement. Journal of Managerial Psychology, 21, 600-619. https://doi.org/10.1108/02683940610690169

Schaufeli, W. B., \& Bakker, A. B. (2004). Job Demands, Job Resources, and Their Relationship with Burnout and Engagement. Journal of Organizational Behavior, 25, 293-315. https://doi.org/10.1002/job.248

Schaufeli, W. B., Bakker, A. B., \& Salanova, M. (2006). The Measurement of Work Engagement with a Short Questionnaire: A Cross-National Study. Educational and Psychological Measurement, 66, 701-716. https://doi.org/10.1177/0013164405282471

Spitzberg, B. H. (1997). A Model of Intercultural Communication Competence. Intercultural Communication: A Reader, 9, 375-387.

Spitzberg, B. H. (2006). Preliminary Development of a Model and a Measure of Computer Mediated Communication (CMC) Competence. Journal of Computer-Mediated Communication, 11, 629-666. https://doi.org/10.1111/j.1083-6101.2006.00030.x

Tabachnick, B. G., \& Fidell, L. S. (2013). Using Multivariate Statistics (6th ed.). Upper Saddle River, NJ: Pearson.

Tate, D. T., Lartey, M. F., \& Randall, P. M. (2019). Relationship between Computer-Mediated Communication and Employee Engagement among Telecommuting Knowledge Workers. Journal of Human Resource and Sustainability Studies, 7, 328-347. https://doi.org/10.4236/jhrss.2019.72021

Wang, B., Liu, Y., \& Parker, S. (2020). How Does the Use of Information Communication Technology Affect Individuals? A Work Design Perspective. Academy of Management 
Annals, 14, 695-725. https://doi.org/10.5465/annals.2018.0127

Windahl, S., \& McQuail, D. (1993). Communication Models for the Study of Mass Communications. London: Longman.

Wright, K. B. (2000). Social Support Satisfaction, On-Line Communication Apprehension, and Perceived Life Stress within Computer-Mediated Support Groups. Communication Research Reports, 17, 139-147. https://doi.org/10.1080/08824090009388760 